\title{
Diagnostics of common rail components based on pressure curves in the fuel rail
}

\begin{abstract}
Majority of modern diesel engines is fitted with common-rail (CR) fuel systems. In these systems, the injectors are supplied with fuel under high pressure from the fuel rail (accumulator). Dynamic changes of pressure in the fuel rail are caused by the phenomena occurring during the fuel injection into the cylinders and the fuel supply to the fuel rail through the high-pressure fuel pump. Any change in this process results in a change in the course of pressure in the fuel rail, which, upon mathematical processing of the fuel pressure signal, allows identification of the malfunction of the pump and the injectors. The paper presents a methodology of diagnosing of CR fuel injection system components based on the analysis of dynamic pressure changes in the fuel rail. In the performed investigations, the authors utilized LabView software and a $\mu D A C$ data acquisition module recording the fuel pressure in the rail, the fuel injector control current and the signal from the camshaft position sensor. For the analysis of the obtained results, 'FFT' and 'STFT' were developed in order to detect inoperative injectors based on the curves of pressure in the fuel rail. The performed validation tests have confirmed the possibility of identification of malfunctions in the CR system based on the pressure curves in the fuel rail. The 'FFT' method provides more information related to the system itself and accurately shows the structure of the signal, while the 'STFT' method presents the signal in such a way as to clearly identify the occurrence of the fuel injection. The advantage of the above methods is the accessibility to diagnostic parameters and their non-invasive nature.
\end{abstract}

Key words: combustion engine, fuel pressure, FFT signal analysis, common rail

\section{Introduction}

Modern Common Rail diesel engines are widely applied in light-duty vehicles, light-duty trucks and heavy-duty vehicles. The currently applied generation of these systems, whose injector design and control, allows executing several injections per single engine work cycle. The first injection (pilot) warms up the combustion chamber and provides a swirl of the charge. Further injections increase the efficiency of formation of the quasi homogenous mixture and reduced the exhaust emissions. The final injection is executed during the exhaust stroke to reduce the emission of particulate matter. A consequence of the nonoccurrence of any of the injections or changes in the proper rail pressure results in limited engine performance and excess emissions. Therefore, quick identification of malfunctions in the fuel system that prevents engine incorrect operation is extremely important [1].

Every time a fuel dose is injected into the cylinder, it immediately results in a drop of pressure in the rail immediately compensated with the help of a high pressure pump and its regulator.

The paper presents the method of analysis of a high pressure sensor signal that enables an assessment of the course of injection and the operation of the pump. This analysis enables identification of malfunctions in the $\mathrm{CR}$ components for different volumes of the pilot (injector opening time $200 \mu \mathrm{s}$ to $400 \mu \mathrm{s}$ ) or the main (injection time in excess of $450 \mu \mathrm{s}$ ) fuel doses $[2,5]$.

\section{Object and methodology of research}

The object of the research was a CR system of a G9T720 engine. The system is composed of a low pressure circuit: fuel tank, fuel pump, fuel cooler, fuel filter, fuel heater and high pressure circuit: high pressure pump, accumulator (fuel rail) and electromagnetic injectors. The control of the fuel pressure in the rail is done through a pressure regulator fitted in the high pressure pump. The fuel is pumped into the rail from which the only outlet are the lines leading to the injectors. The pressure in the rail is measured by a pressure sensor. The injectors are supplied with fuel under the same pressure as the one in the rail. The value of the pressure and the opening time of the injector are decisive of the dose of injected fuel, which translates into instantaneous pressure variations in the rail.

The fuel rail is fitted with a standard $5 \mathrm{~V}$ Bosch pressure sensor. The signal from the sensor is received through wires connected to terminals 2 and 3. In order to measure the instantaneous pressure in the rail, an ADPT-25-S connector of the $\mu$ DAQ USB-26 data acquisition module (Eagle Technology) was connected to the control unit with the existing wires. The signal was sent via a USB port to the computer running the LabView application. The investigations were carried out in two stages:

- on the test stand, which allowed a validation and optimization of the software for the signal analysis and performance of reconnaissance tests,

- on the G9T engine operating on the engine dynamometer, which enables a validation of the developed methodology.

In the first stage of the investigations, the measurements were carried out on the STPiW-2 test stand (Fig. 1) designed for testing of CR system components. Components of the CR system from the Renault G9T engine were installed on the test table. The measurements aimed at determining the operating characteristics of the fuel systems and configuring the 'VI' (virtual instrument) software developed in LabView whose job was to diagnose the CR system components, [5]. Another precise AVL SL31D2000 sensor was fitted on the fuel rail along with the conditioning equipment to compare the pressure curves and evaluate the accuracy of the pressure reading of the standard pressure sensor.

During the investigations, two measurement strategies were applied and validated differing with the method of analysis of the signal from the pressure sensor and the 
method of presentation of the results. For both methods, the programs were developed in the LabView environment $[2,3]$.

a)

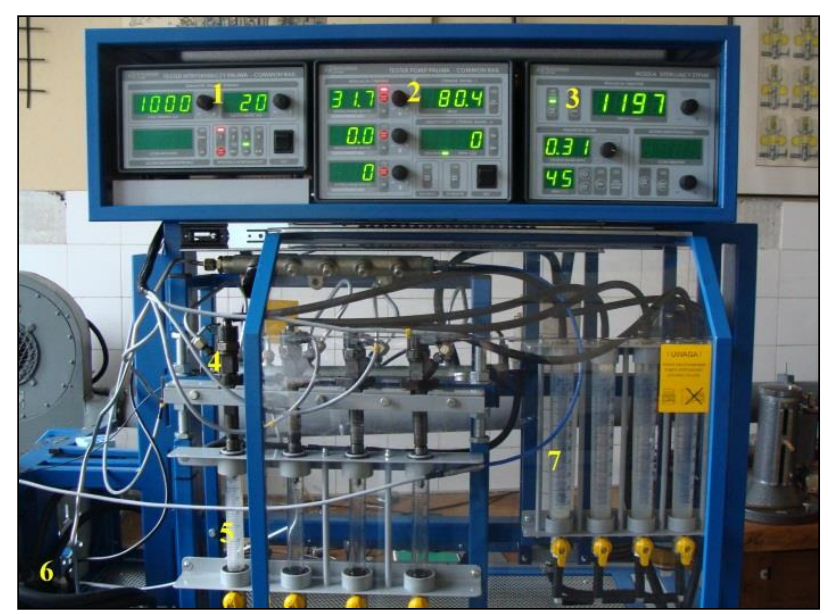

b)

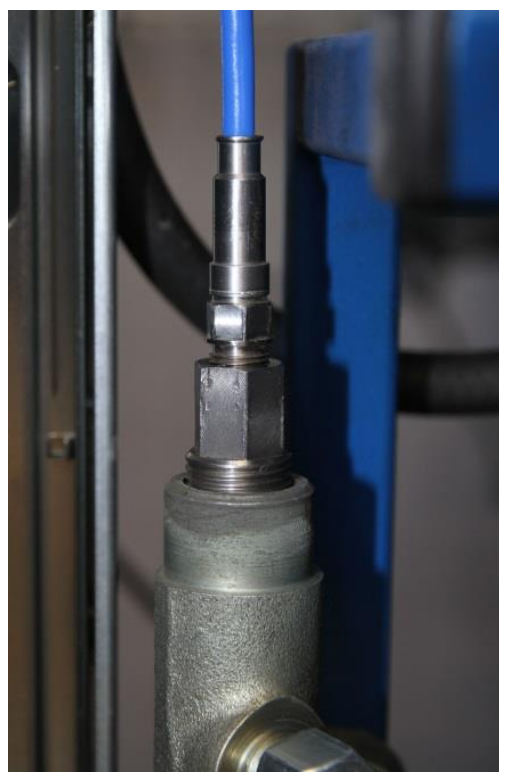

Fig. 1. STPiW-2 testing table: a) general view, b) AVL SL31D2000 pressure sensor fitted in the adapter: 1 - fuel injector tester, 2 - high-pressure pump tester, 3 - testing table control module, 4 - injectors, 5 - fuel dose measurements cylinders, 6 - high-pressure pump, 7 - overflow measurement cylinders

The first method is based on a fast Fourier transform (FFT) and low-pass signal filtering. The block diagram of the 'FFT' has been presented in Fig. 2. The software allows configuring the settings of the data acquisition module (sampling frequency, number of samples, upper and lower measurement range). In this method, one constant component of the rail pressure signal (being its average value) was subtracted from that signal. The modified signal underwent a discrete Fourier transform that enables observing the signal in the amplitude-frequency coordinates [3]. Such a graph shows, from which constant harmonic components the signal is composed and what the value of the amplitude is. In order to catch a clear reading without static, a lowpass filter was applied. The effect has been presented in Fig. 4.

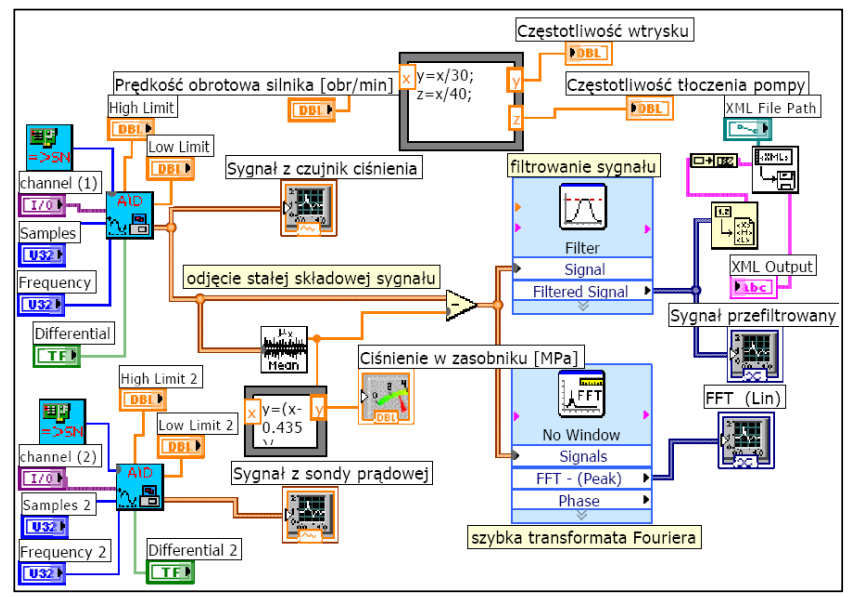

Fig. 2. Block diagram of 'FFT'

The second method is based on a short term Fourier transform (STFT). The block diagram of the 'STFT' has been presented in Fig. 3. The data acquisition module can be configured similarly to 'FFT'. The constant component (average value) of the signal was subtracted from it. Then, the signal underwent a low-pass filtering and a short term Fourier transform. The brightness of individual streaks (Fig. 5) shows the value of the amplitude of the signal components. The program allows setting the parameters for the analysis during the transform, which is impactful on the type of information presented in the graph. Depending on the setting, we may determine the time, in which the signal values are changed or precisely determine the frequency of the harmonic signal components.

In the first stage of the investigations, the validation tests were performed on the testing table (Fig. 1a). It allowed a free control of the following parameters: rotational speed of the high-pressure pump, pressure in the fuel rail, injector opening time and injector opening frequency. The validation of both methods consisted in comparing the parameters set at the system input (settings in the control panel of the testing table) with the results of the analysis of the pressure change in the fuel rail. Both methods were tested for small (pilot) and large (main) fuel doses.

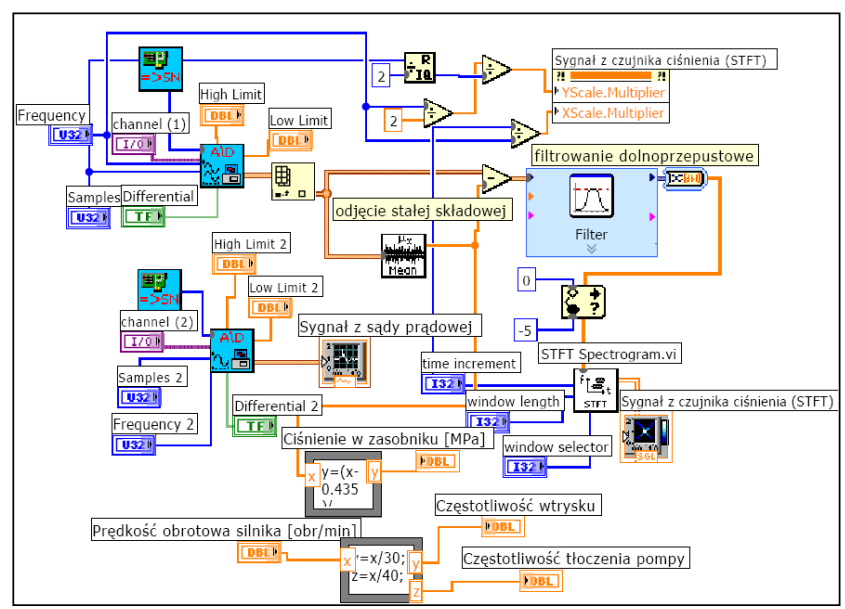

Fig. 3. Block diagram of 'STFT' 


\section{Results}

In the first stage, validation tests were performed for the main fuel doses on the testing table. In order to validate the method, the following parameters were set:

- rotational speed of the high-pressure pump: $1200 \mathrm{rpm}$;

- injector opening frequency:

- injector opening time:

- fuel pressure in the rail:

$20 \mathrm{~Hz}$;

$1000 \mu \mathrm{s}$

$80 \mathrm{MPa}$.

The sampling parameters of the signal were selected in such a way as to analyze a fragment of the signal of the duration of $0.1 \mathrm{~s}$. During this time, two injections were executed. On the graph of the filtered signal (Fig. 4a), we can clearly see two steep drops in the fuel pressure in the rail that indicate the occurrence of the injections. On the FFT graph (Fig. 4b), the components of the signal frequency have been presented. Aside from the injector opening frequency, there is a component related to the frequency of the fuel pumping in the high-pressure section that allows an evaluation of the correct pump operation. Since the results of the analysis of the obtained signals confirmed the settings of the parameters on the testing table, the authors concluded that the first method is good for detecting of the main doses.

a)

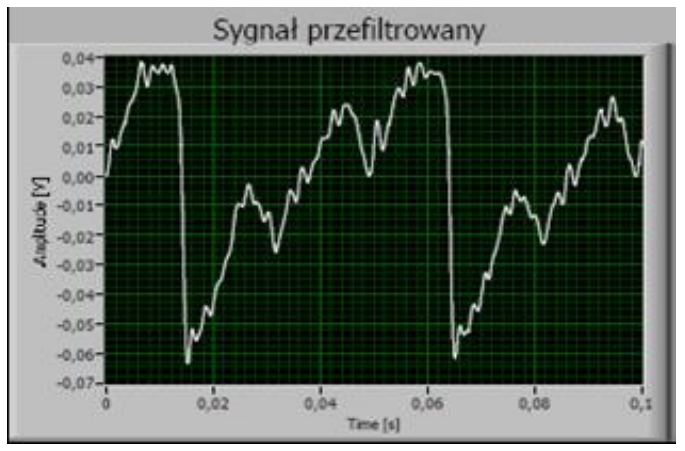

b)

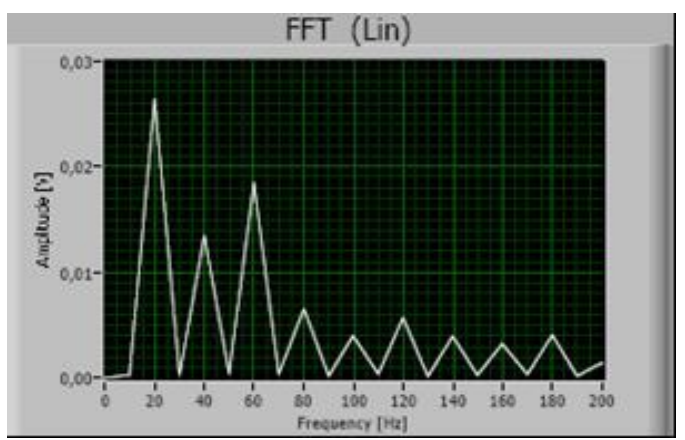

Fig. 4. The 'FFT' method. Signal curve in the domain of: a) time, b) frequency for the main fuel doses

During the validation of the 'TFT' method, the sampling parameters were identical as in the first method. At the moment of occurrence of the fuel injection, streaks of different hues of blue appear on the graph depending on the fuel pressure amplitude in the rail (Fig. 5). On the time scale, we can clearly see that the injections take place at even time intervals, which corresponds to the frequency of $20 \mathrm{~Hz}$. The advantage of this method is that the information

on the occurrence or non-occurrence of the injection was isolated from the signal. This method is also appropriate for detecting the main fuel doses.

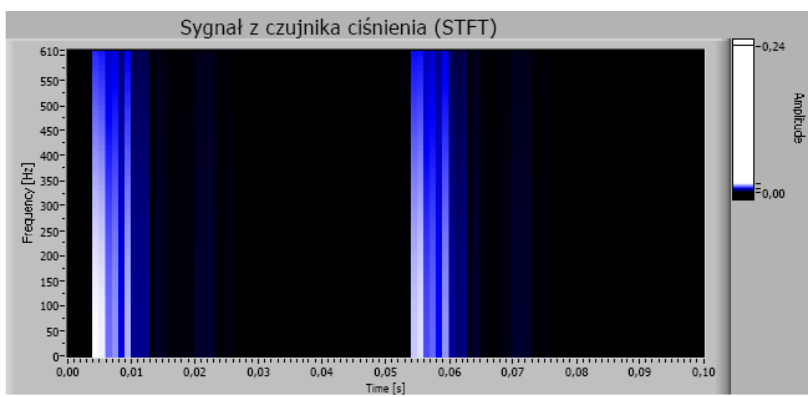

Fig. 5. The 'STFT' method. The STFT graph of the signal from the pressure sensor for the main fuel doses

The next step was the validation of the small doses on the testing table. In order to validate this method, the following parameters were set:

- rotational speed of the high-pressure pump $400 \mathrm{rpm}$,

- injector opening frequency

- opening time of the injector

- fuel pressure in the rail

$20 \mathrm{~Hz}$, $300 \mu \mathrm{s}$, $40 \mathrm{MPa}$.

As for small fuel doses, the pressure drops are miniscule, hardly seen on the time curve and the highpressure pump rapidly compensates them (Fig. 6a). On the FFT graph (Lin) (Fig. 6b) a component frequency is visible that is triggered by the injection, yet, the filtered signal is unclear, which may result in difficulties when identifying faulty injectors.

a)

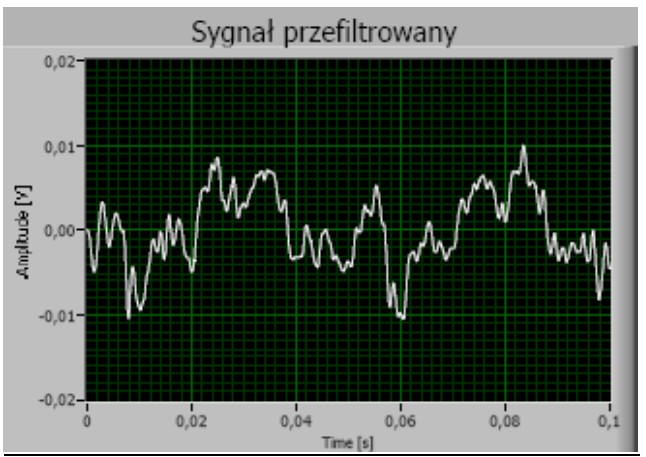

b)

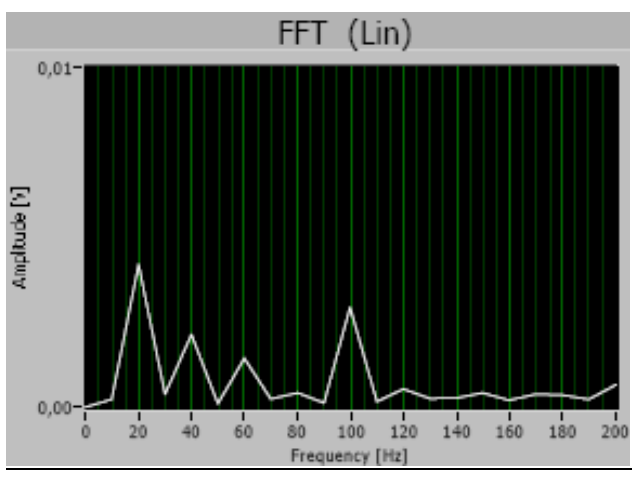

Fig. 6. The 'FFT' method; signal curve of the fuel pressure in the rail for small fuel doses in the domain of: a) time, b) frequency 
When the STFT method was applied (Fig. 7), two injections were recorded at a 0.05 second interval. The indications are not as clear as they are for the main fuel doses, but they allow confirming the occurrence of two subsequent injections. This information is sufficient to deem this method as good for detecting small fuel doses.

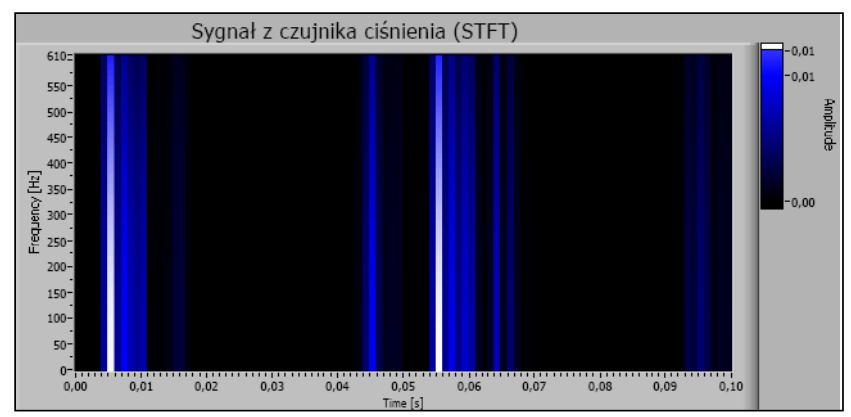

Fig. 7. The 'STFT' method. STFT graph of the signal from the pressure sensor for small fuel doses

Next, the validation of the developed method was carried out on the Renault G9T engine installed on a dynamometer. The investigations were first carried out on an injection system having all injectors operative. The engine started easily and operated at idle with the speed of 800 rpm.

The signal and its spectrum recorded in 'FFT' has been presented in Fig. 8. The signal curve is correct. There are small deviations of the amplitude interrupted with cyclic steep peaks occurring at the moment of injection. The pump and the injectors' operating frequency at the set engine speed should be $20 \mathrm{~Hz}$ and $27 \mathrm{~Hz}$ respectively.

a)

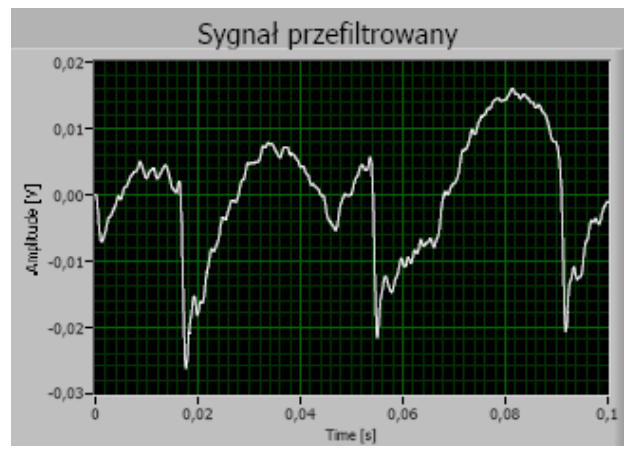

b)

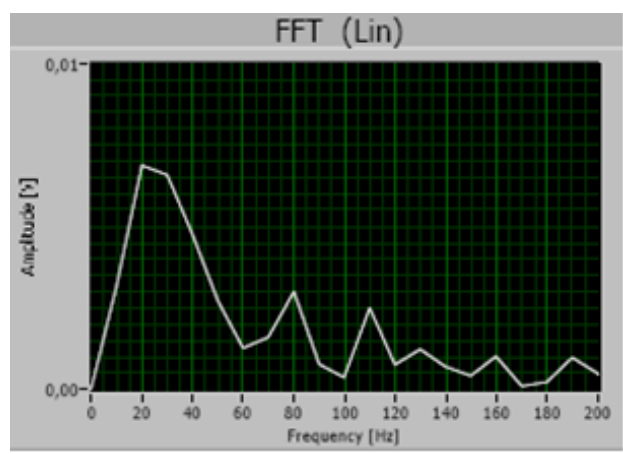

Fig. 8. Measurement of the signal performed with 'FFT' (all injectors operative)
The fuel pressure in the rail was approx. $35 \mathrm{MPa}$. On the spectrum, we can see that the main signal components are $20 \mathrm{~Hz}$ and $26.7 \mathrm{~Hz}$. The signal recorded in 'STFT' has been shown in Fig. 9. The bright streaks on the spectrum clearly show at which moment the injections occurred. The cyclicity of occurrence of the streaks corresponds to the frequency of operation of the injectors. The information on the occurrence of an injection presented in the 'STFT' graph clearly (as in a zero-one method) determines whether the injection was executed or not.

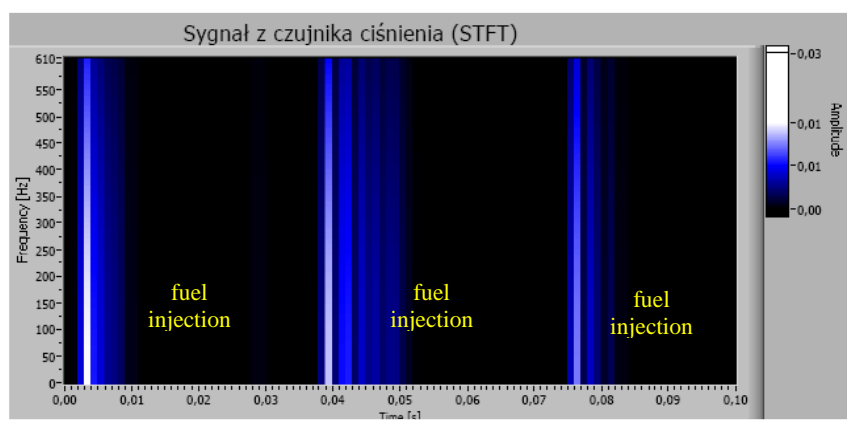

Fig. 9. Measurement of the signal performed with 'STFT' (all injectors operative)

The next step was a simulated fuel injector malfunction in the first cylinder. A control module wiring was disconnected from the engine injector and connected to a separate one. The wire could not have stayed disconnected because the signal from the control module must reach the injector for the engine to start. The simulated malfunction reflects a situation of a faulty injector (seizure). The control module sends a signal to the injector but the injection to the cylinder is not executed.

The engine started properly and operated at idle with the speed of $800 \mathrm{rpm}$. The engine was louder and a higher vibration of the engine block was observed. The settings of the measurement equipment were the same as for the tests described earlier in the paper.

In the first place, the signal from the pressure sensor was analyzed in 'FFT'. On the time tracing of the signal (Fig. 10a) we can see one peak missing caused by the lack of injection. Instead of the downward peak, there is a smooth drop in the amplitude. The signal spectrum clearly differs from the one in Fig. 9. The highest peak occurs for the frequency of $10 \mathrm{~Hz}$, i.e. for the signal frequency caused by the lack of injection (Fig. 10a).

In order to facilitate the injector diagnostics, the signal from the sensor was subjected to an analysis in 'STFT'. In the signal spectrum, the bright streaks indicate when the injection was executed. Fig. 10 shows that only two streaks appeared instead of three. Additionally, between some of the streaks a long interval was visible resulting in uneven streak occurrence. These are evident symptoms of a malfunctioning injector.

Upon diagnosing of a malfunction of one of the injectors, the faulty injector must be identified without removing all of the injectors from the engine. To this end, an additional diagnostic parameter was measured - the injector supply current. The current probe was connected to channel 2 of the microDAQ module. 
a)

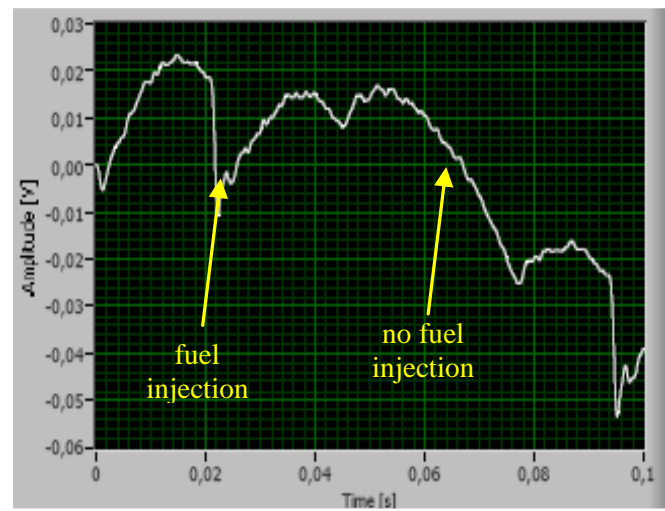

b)

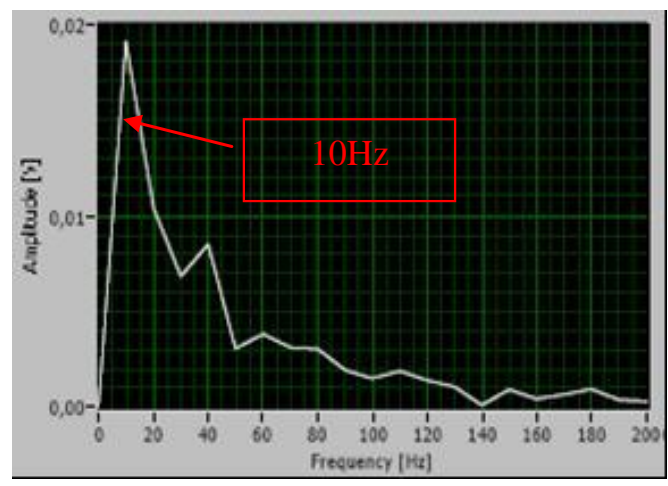

c)

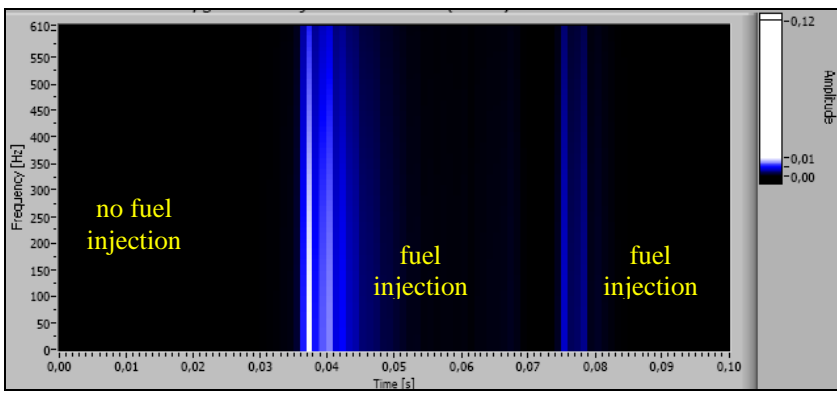

Fig. 10. The 'FFT' method (one injector inoperative): a) pressure curve in the fuel rail, b) signal spectrum, c) STFT curve of the pressure signal for one injector malfunctioning

Both signals were recorded on the graphs with the same time interval, one after another, to easily refer the current reaching the coil to the injection. The injectors are diagnosed one after another and monitored whether the supply current triggers the injection, which is seen as a pressure drop. If there is a supply current and the signal from the pressure sensor on the time line is not reflected as a steep drop of pressure, it means that the injector is faulty. One should note the delay between the supply current and the pressure signal. The inertia of the injector components results in the delay at the moment of activating and deactivating of the injector. A simultaneous recording of the two parameters in 'FFT' has been presented in Fig. 11.

In order to facilitate the method of identifying the faulty injector, 'STFT' was applied, in which we can observe the induction signal in the form of a supply current and the system response in the form of a bright streak resulting from the injection (Fig. 11). The current probe was fitted on the wiring of the faulty injector. The signal curve of the probe seen in the lower screen indicates that the injector is electrically functional. It is not hydraulically functional though, because at the moment when the supply current is sent, as seen on the upper screen, the bright streak does not appear, which is tantamount to the lack of injection.

a)

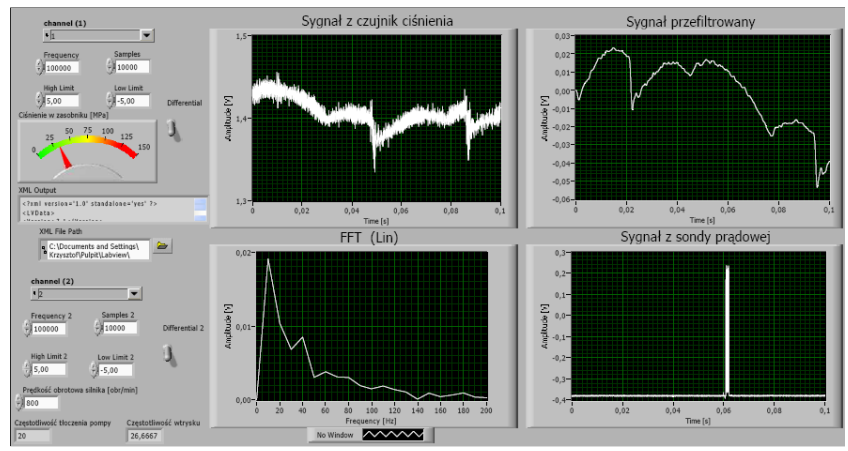

b)

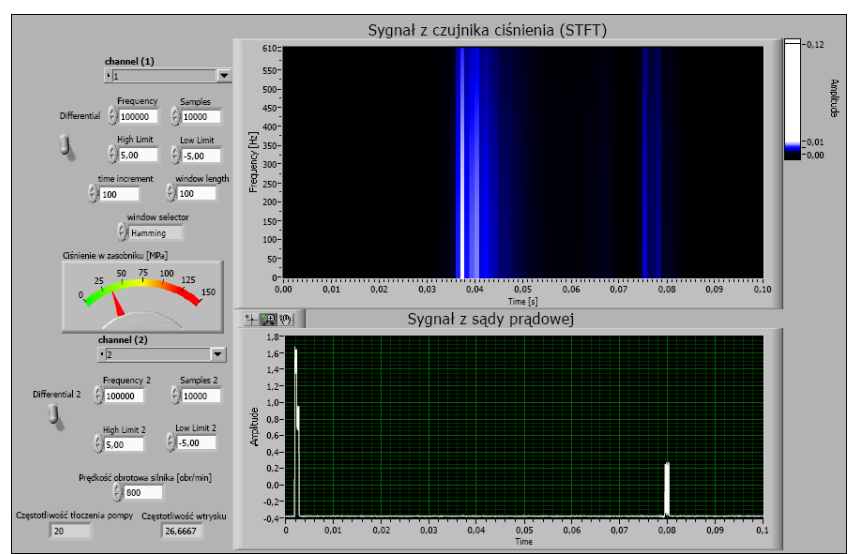

Fig. 11. View of the program windows: a) simultaneous recording of the pressure in the rail and the supply current of the injector, b) detection of the faulty injector with 'STFT'

To confirm the applicability of this method, an additional test was carried out for the engine speed of $1200 \mathrm{rpm}$, only this time the operative injector was replaced with a seized one. The injector operating frequency for a given engine speed should be $40 \mathrm{~Hz}$, i.e., four injections should take place within $0.1 \mathrm{~s}$. On the screen, only three streaks appear, which indicates that one injector is not injecting fuel.

The faulty injector was identified by the measurement of the supply current of the subsequent injectors. The current probe was connected to the first injector. On both screens we can see a convergence of signals consisting in an almost simultaneous presence of the current signal and the streak indicating the pressure drop. This confirms that the first injector is hydraulically and electrically functional. After excluding the first injector the probe was connected to the second one. As of the moment when the supply current reaches the injector, there is no streak on the upper screen, which indicates a lack of the fuel injection into the cylinder. The injector is hydraulically inoperative. The applied method allowed identifying the faulty injector. 
In between two signals, in a properly operating injection system, four injections should take place numbered as in the firing order of the cylinders. The lack of the downward peak (pressure drop) in the 'FFT' method and the lack of the streak in the 'TFT' method may be directly referred to the faulty injector.

\section{Conclusions}

The analysis of the signal from the high-pressure sensor allows an assessment of the course of the injection and the process of pumping by the supply pump. This analysis allows identification of malfunctions of components of the CR injection system for different volumes of both the pilot and the main fuel doses

The described types of software outrank oscilloscopes with their potential as they can be constantly expanded with new functionalities to improve the diagnostic process. The development of software should aim at the improvement of

\section{Bibliography}

[1] GUNTHER, H. Diagnozowanie silników wysokoprężnych. WKiE, Warszawa 2014.

[2] KARCZEWSKI, M., KOLIŃSKI, K. Diagnostyka wtryskiwaczy układu Common Rail na podstawie pomiarów ciśnienia w zasobniku. Zeszyty Naukowe WSOWL. 2011, 1(159).

[3] PAYRI, F., LUJÁN, J.M., GUARDIOLA, C. et al. Injection diagnosis through common-rail pressure measurement. Proceedings of the Institution of Mechanical Engineers. 220 Part D: Journal Automobile Engineering.

\footnotetext{
Mirosław Karczewski, DEng. - Faculty of Mechanical Engineering at Military Academy of Technology.

e-mail: Miroslaw.Karczewski@wat.edu.pl
}

potential in the analysis of the acquired data and autonomous reporting of the diagnostic results. This would be more time efficient and would reduce the costs of workshop diagnostic equipment.

Both methods are applicable in injection systems diagnostics. The 'FFT' method provides more information related to the operation of the system itself and accurately presents the structure of the signal. The 'STFT' method presents the signal in such a way as to clearly indicate the execution of an injection. An advantage of the said methods is the accessibility to the diagnostic parameters. For the pressure measurement, both methods utilize a factory made sensor originally fitted in the fuel rail.

It is justified to continue further research aiming at confirmation of the applicability of the developed methods for other types of Common-Rail fuel systems.

[4] TŁACZAŁA, W. Środowisko LabVIEW w eksperymencie wspomaganym komputerowo. WNT. Warszawa 2002.

[5] Poradnik Serwisowy. Zasilanie silników HDI, 2004, 4, Wydawnictwo Instalator Polski.

[6] Zasobnikowe układy wtryskowe Common Rail. WKiE, Warszawa 2005.
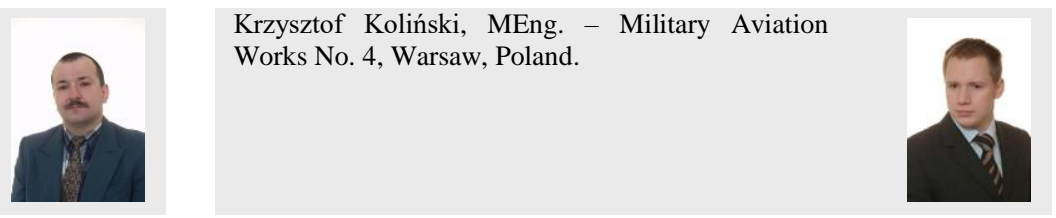